\title{
Cidades Inteligentes são Cidades Saudáveis?
}

Dossier DE PESQUISA : CidADE SAUdÁVEL

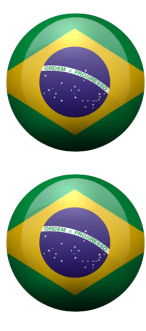
Marcia Maria Arco e Flexa Ferreira da Costa

Psicóloga, Mestre e Doutoranda em Educação, Arte e História da Cultura, pela Universidade Presbiteriana Mackenzie. Pós graduada em Docência da Língua Inglesa; em Comunicação Organizacional e Relações Públicas; em Recursos Humanos. São Paulo [SP] Brasil <marciaflexa@gmail.com>.

\section{Cláudia Coelho Hardagh}

Professora do Programa de Pós-graduação em Educação, Arte e História da Cultura, da Universidade Presbiteriana Mackenzie. Pós-doutora pela Universidade de Coimbra. Doutora pela PUC-SP. Historiadora, Socióloga e Pedagoga. São Paulo [SP] Brasil <hardagh@gmail.com>.

\section{Resumo}

O objetivo deste artigo se funda em pensar as práticas e os apelos aparentemente "mágicos" da tecnologia para a cidade inteligente e a sua contribuição para a realidade da cidade saudável. A reflexão ocorre a partir da exploração de conceitos de obsolescência produtiva, hibridismo humano-tecnológico e conexão digital que se desenvolvem excluindo pessoas iletradas tecnologicamente. Analisar a contribuição da tecnologia na cidade e na cidadania em um cenário disruptivo permite compreender se a cidade está sendo construída para produzir e controlar ou para promover a convivência de maneira saudável e coletiva. Propõe-se primeiro, explorar os conceitos de tecnologia, obsolescência e conexão digital. Em segundo lugar, refletir sobre as ferramentas de inteligência tecnológica e a sua relevância nos centros urbanos saudáveis. Em terceiro lugar pensar se a relação de tecnologia e urbanização é de fato benéfica para a cidade e o cidadão. As perguntas essenciais são: Como se dá a obsolescência produtiva? Podemos nos apoiar na tecnologia para uma cidade saudável ou apenas smart? Esta pesquisa pretende, portanto, oferecer subsídios para uma reflexão acerca dos caminhos alternativos na educação do cidadão sem se deixar seduzir pelo apelo Tech de cidades inteligentes.

\section{Palavras-chave}

Cidade Inteligente. Cidade Saudável. Tecnologia. Obsolescência.

\section{Smart Cities are Healthy Cities?}

\begin{abstract}
The purpose of this article is critical for the practices and goals to be "magical" appeal for technology to an intelligent city and its contribution to a healthy city reality. The reflection occurs from the exploration of concepts of productive obsolescence, human-technological and digital hybridism that is developed excluding technologically illiterate people. Analyzing if the situation of technology in the city and citizenship in a disruptive health scenario can be in fact understood as a city built for progress and programmed to promote a healthy and collective coexistence. It is proposed first, to explore the concepts of technology, obsolescence and digital connection. Second, reflect on the tools of technological intelligence and their relevance in healthy urban centers. Third, it is questioned if the relationship between technology and urbanization is in fact being beneficial for the city and the citizens. Essential questions: How does productive obsolescence occur? Can we rely on technology for a healthy city or just a smart city? This article therefore intends to grant subsidies for an investigation into alternative ways of educating citizens without being seduced by the appeal.
\end{abstract}

\section{Keywords}

Smart City. Healthy City. Technology, Obsolescence. 


\section{Introdução}

Resolver problemas complexos em diversas esferas, até aqui, fez parte da constituição essencial do que nos distinguiu como seres humanos, no entanto, a partir do desenvolvimento da tecnologia digital, artificial e neural e o aumento dos dados e informações referentes a tudo e a todos, a complexidade e a conectividade já não são mais desafios eminentemente humanos e são cada vez mais contemporâneos. Temas concernentes ao próprio ser humano, às relações, à educação, à sociedade e aos espaços, entre outros, eram questões humano-cognitivas, atualmente são desafios humano-mecânico-tecnológicos e, em breve, serão soluções mais tecnológicas do que humanas(cf.: <https://www.forbes.com/sites/tomvanderark/2018/06/26/how-cities-are-getting-smart-usingartificial-intelligence/\#79bca57e3803/; recuperado em 26 de novembro, 2018>).

Embora atualmente muitos tenham se debruçado muito sobre a ética e a Internet das coisas, a ética digital e as relações humano-robóticas, as inteligências e o "cibermundo", há, por outro lado, temas sempre atuais, tais como:habitação, habilidades humanas, espaços de convivência, relacionamento e diálogos multidisciplinares e transdisciplinares que se tornaram de segunda relevância, apesar de imprescindíveis na sociedade que se reconfigura exponencialmente em função do espectro tecno-digital e comercial.

Nesta reflexão problematizamos o fascínio pela tecnologia, automatização e inteligência artificial em especial na cidade saudável em contrapartida com o ser humano que pode ganhar um status potencialmente improdutivo nas cidades tecnológicas em virtude de não estar apto para o mercado tecnológico ou por perder espaço para a automação inteligente e controladora das cidades e porque as relações pessoais parecem mais efêmeras, mais fluidas, mais rasas e sufocadas pela sedução da conexão desconectada que a internet parece oferecer.

\section{A Tecnologia}

A tecnologia estabelece uma imbricação sistêmica entre muitos campos de pesquisa, por encontrar-se presente desde a extração da matéria-prima até o produto final, incluindo a conexão das partes, inferências no processo, a regulação das relações até a criação do produto, distribuição, consumo e controle. Desse modo, a tecnologia conectiva digital tem mudado as relações e o cenário urbano reciprocamente de forma indelével, modelando, aprendendo, processando informação, planejando e manipulando dados, entretanto, os cidadãos não percebem a atuação generalizada e massiva da tecnologia no controle de suas vidas e das cidades.

Os seres humanos são lineares, embora caóticos, pensam temporal e processualmente, e, ao mesmo tempo, relacionam-se através de histórias e símbolos, reinventando-se e atuando de maneira dinâmica. Ao passo que as máquinas, os computadores são binários, algorítmicos, lógicos e não desligam. Em essência, a máquina quer a perfeição humana ao buscar, por exemplo, reproduzir as conexões sinápticas, neurais e bioquímicas, porém, em nível exponencial, ininterruptos e com perfeição. Os humanos conseguem ser instintivos e dedutivos, a máquina é desenvolvida para "querer" ser inteligente e adaptativa, e desenvolvida para replicar a capacidade de adaptação dos humanos em nível de perfeição técnica.

Este percurso impressionante e dinâmico é vivido e refletido na cidade e na relação entre homem e máquina, entre urbano e rural, entre o verde (eco) e a cinza (máquina), entre as gentes e os computadores, entre os macro espaços e os micro lugares. A cidade precisa de livability, workability e sustainability de forma que as pessoas se integrem transformando o ambiente com qualidade e saúde para que todos convivam e trabalhem, produzam e consumam harmonicamente em espaços saudáveis, realmente coletivos, amigáveis e prazerosos. Convém ressaltar que o conceito de cidade saudável desta reflexão é o utilizado pelo Movimento Cidade Saudável (cf.: <http://www.scielo.br/scielo.php?script=sci_arttext\&pid=S1413-81232000000100006/; recuperado em 28 de novembro, 2018>) que nasceu criando as bases para promoção da saúde no contexto urbano e local.

No processo de construção de uma cidade saudável, a participação significa uma postura ativa de envolvimento e corresponsabilidade dos diversos saberes, setores técnicos e 
segmentos sociais da população na discussão dos problemas da cidade e na tomada de decisão sobre as formas de enfrentamento dos mesmos, construindo, dessa forma, um projeto mais ampliado e real para a cidade. Além disso, é a participação que dá legitimidade política e social a esse projeto (cf.: <http://www.scielo.br/scielo.php? script=sci_arttext\&pid=S1413-81232000000100006/>).

Um município saudável, de acordo com a OPAS, é aquele em que [...]

[...] as autoridades políticas e civis, as instituições e organizações públicas e privadas, os proprietários, empresários, trabalhadores e a sociedade dedicam constantes esforços para melhorar as condições de vida, trabalho e cultura da população; estabelecem uma relação harmoniosa com o meio ambiente físico e natural e expandem os recursos comunitários para melhorar a convivência, desenvolver a solidariedade, a cogestão e a democracia (OPAS, 1996, p. 102).

Este talvez seja o grande desafio das cidades hoje, pois é nesta que todos se encontram e se desencontram. Na cidade tudo acontece, é o lócus de convivência das pessoas e das marcas, dos governos, das escolas e comunidades e também dos grandes e pequenos enfretamentos individuais e coletivos. A cidade vive em escala geométrica os problemas dos pequenos coletivos, questões emblemáticas em todas as diferentes esferas, seja o aumento do desemprego e o crescimento da ocupação comercial informal; a distribuição de renda desigual em diferentes bairros, camadas da sociedade ou mesmo entre gêneros; a questão da privacidade cada vez mais questionada é difícil em cidades que crescem conectivamente com seus "smart-tudo" (vídeos, câmeras, fones, mic, apps etc.); a ocupação, a violência, o uso de drogas, a corrupção, a ganância de quem compra o espaço público e o comercializa, as instituições e seus governos, a chegada das gentes de todas as etnias, hábitos, crenças e desejos; o crescimento desordenado, a sujeira e o descarte, a fartura e a miséria, o transporte público e a educação.

Tudo na cidade clama pelo humano e grita pelo tecnológico que potencialmente pode facilitar, abrir acessos e conectar pessoas. Isto quer dizer que é preciso encontrar um modo equilibrado de usar a tecnologia a favor da cidade para gestão e comunhão do espaço público de forma inteligente e elegante gerando convivência e saúde no seu sentido mais amplo. 0 exercício de pensar a cidade, arte, a educação e a tecnologia pode ser, neste artigo, uma reflexão para explorar esta conexão e imbricação contínua e crescente. Na arte, a criação e a imaginação, os espaços e escopos antes podiam ser balizados para definirem os seres humanos criadores e distingui-los dos demais animais, tidos como instintivos, ou das máquinas, vistas como fios e linhas de programação no sentido mais raso.

Mas o ser humano, especialmente urbano, tem o seu lócus alterado e a sua funcionalidade questionada. Hoje, em velocidade alarmante, humanos são seduzidos e apanhados por um número crescente de produções artísticas, inéditas ou reproduções na pintura, escultura, mosaicos, música e demais expressões artísticas feitas por mãos eletrônicas, códigos, softwares, inteligências artificiais, portanto, não humanas que se relacionam entre si, com os humanos e com a cidade de outras e diferentes maneiras.

A IBM Watson (cf.: <https://www.huffpostbrasil.com/entry/ibm-ai-watson-wrote-lexuscommercial-car-comes-alive_us_5bf2f3f2e4b0b84243e4e968/>, recuperado em 12 nov. 2018), por exemplo, já usou inteligência artificial para criar o primeiro roteiro de comercial de carros de luxo da marca Lexus (cf.: <https://www.youtube.com/watch?time_continue=57\&v=4a1kojUzKE4/>, recuperado em 12 nov. 2018) a transitar pelas ruas das cidades. 0 computador foi alimentado por diversas peças e textos premiados nos últimos 15 anos e, segundo a equipe de produção, o roteiro estava bastante apropriada. A apropriação da tecnologia pode ser mais invasiva em outros casos, quando, por exemplo, a Inteligência artificial ajuda a escolher a música na medida em que as marcas usam a análise de DNA e um robô para fazerem a curadoria de playlists(cf.: <https://www1.folha.uol.com.br/tec/2018/10/inteligencia-artificial-ajuda-a-escolher-amusica-certa.shtml/>, recuperado em 6 nov. 2018).

Na cidade é abundante a inserção e as projeções para os avanços da tecnologia. As já conhecidas cidades inteligentes recolhem dados de todas as formas, independente de haver consentimento, 
seja por formulários preenchidos voluntariamente, sensores, câmeras, áudios, APPs, localizadores, monitoramento de pressão, temperatura, umidade, poluição, ruído, captação e controle de multas e infrações, cruzamento de dados dos cidadãos e seus bens, sistema de GPS e tantas outras maneiras. Os dados se tornam informações usadas por diversos segmentos e também pelo governo. As cidades são um espaço farto para o crescimento de tecnologias conhecidas como IOT (Internet of Things) onde tudo se conecta com diferentes níveis de acesso.

Ao analisar um enorme volume de dados é possível identificar tendências e padrões, rotinas e até desvios que melhoram e pioram as operações urbanas e a prestação de serviços. A inteligência artificial, as redes neurais artificiais que buscam a perfeição do cérebro com a exponencialidade da máquina e as máquinas que aprendem com ou sem humanos, funcionam cada vez mais minerando e analisando os incontáveis pontos de acesso e dados coletados. Todo este input é calculado com o maior grau de precisão possível dentro de sua complexidade para que indique estatísticas, probabilidades, frequências, cores, sabores, espaços até chegar ao nível do individuo e fazer o processo contínuo do micro para o macro, do macro para o micro e, portanto, do controle.

Obstáculos como criação, espaço, tempo e as distâncias serão cada vez mais percorridos com velocidade e inovação e, devido a esta rapidez quase autônoma, onde a percepção, a criticidade e a compreensão dos fenômenos e das relações desta espacialidade, temporalidade e humanidade serão conceitos de difícil compreensão e domínio para o cidadão que não participar da elaboração da solução de problemas, tornando-se, por outro lado, apenas expectador e consumidor do produto pronto, da cidade, da educação e da sociedade acabada. Se, por um lado, cresce a maneira inovadora ou disruptiva de resolver problemas e criar soluções inteligentes, por outro, problemas de diversas ordens atingem um número geométrico de pessoas e acontecem em escala mundial, não sendo apenas questões locais ou isoladas.

Estes problemas deixam de ser apenas físicos e naturais, e atingem o âmbito do comportamento, da mente, da ética, da educação, da história e das relações humanas e, por isso, são questões pedagógicas que abrem espaço para discutir uma potencial obsolescência produtiva do ser humano, uma vez que a tecnologia tem atuado e crescido onde humanos eram os únicos e tem ido a lugares onde humanos sequer chegarão ou conseguirão chegar com a mesma velocidade e precisão, deixando para trás uma massa de pessoas potencialmente desempregada, desocupada, improdutiva e digitalmente iletrada que vive dentro desta disrruptividade sem se dar conta desta ou que sequer está inserida neste mundo conectivo. Do micro ao macro, da casa à escola e de lá para as instituições e os governos das cidades, todos vivemos em "cidades mundos" desiguais e vorazmente complexos.

\section{A obsolescência}

A obsolescência consiste em um termo mais comum na língua inglesa e remete tradicionalmente ao serviço, bem ou produto que passa a ser inútil, mesmo se puder ser usado ou se estiver em bom funcionamento, por causa do aparecimento de algo tecnologicamente melhor, mais eficiente, mais atual (UrzeliaInza, 1998).

A obsolescência planejada é também um termo comum e preceituado no Código de Proteção e Defesa do Consumidor Brasileiro1, visto que os produtos são programados para durarem um determinado tempo, para então serem substituídos, acarretando o consumo de um novo bem, produto ou serviço. A prática consumista é assim estimulada pelo mercado e pelo sistema que diminui a vida útil de um produto em detrimento do outro em vista do lucro.

0 fenômeno industrial e mercadológico da obsolescência programada tem a sua origem na década de 20, quando o presidente da General Motors buscou desenvolver nos consumidores o hábito da constante troca de automóveis, tendo como expediente a alteração anual dos respectivos modelos e acessórios.

\footnotetext{
1 Art. 13. Serão consideradas, ainda, práticas infrativas, na forma dos dispositivos da Lei no 8.078, de 1990: XXI — deixar de assegurar a oferta de componentes e peças de reposição, enquanto não cessar a fabricação ou importação do produto, e, caso cessadas, de manter a oferta de componentes e peças de reposição por período razoável de tempo, nunca inferior à vida útil do produto ou serviço.
} 
Surgiu, então, o processo da descarte, utilizado pelos países capitalistas nas décadas de 30 e 40 que, tendo em vista a retomada do crescimento econômico, produziam bens de consumo com durabilidade reduzida, levando o consumidor a adquirir novos produtos em intervalos menores de tempo (cf.: <http://ambito-juridico.com.br/site/?n_link=revista_artigos_leitura\&artigo_id=19185/ $>$, recuperado em 28 nov. 2018).

Por sua vez, a expressão "obsolescência humana" é também usada por Marilda Merência Rodrigues em sua tese de doutoramento em 2008, na qual desenvolve a conceituação de obsolescência como sendo $[\ldots]$

[...] a educação ao longo da vida instituída como política educacional sustenta-se numa concepção de tempo e história que visa a construção de uma nova subjetividade, de um sujeito em eterna obsolescência (Rodrigues, 2008,p. 45).

[...] assim, constrói-se gradativamente a ideia de obsolescência curricular e de uma cultura escolar não significativa por meio de inúmeras "constatações" de que a baixa qualidade da educação, precisamente escolar e pública, e seus conteúdos não conseguem dar respostas suficientes à demanda por produção de conhecimentos em nível mundial e às mudanças no mundo do trabalho (Rodrigues, 2008,p. 89).

A multiplicidade dos problemas, a magnitude, a especificidade das questões humanitárias e a complexidade espaço-temporal dos problemas urbanos e rurais, sejam mundiais ou locais, criará um abismo ocupado por humanos produtivamente obsoletos, uma vez que muitos estarão despreparados para as exigências produtivas das cidades digitais e tecnológicas. Indivíduos que moram em centros urbanos, onde esta realidade é pujante, e imersos no iletramento digital, incapazes de se autogerirem e sustentarem-se em um mundo articulado por grandes marcas, gurus e máquinas inteligentes que aprendem, com ênfase no consumo, reduzindo o cidadão a expectador e consumidor, terão seus dias marcados por um futuro incerto e preocupante.

Embora exista muito entusiasmo e sedução com o potencial e o alcance das tecnologias nos mundos e cidades inteligentes, há muito para se pensar sobre o ecossistema realmente saudável e a respeito do alcance, escalonamento, equilíbrio, prazos, financiamento, sustentabilidade e envolvimento de toda esta tecnologia com todas as pessoas, uma vez que o acesso, a compreensão e a situação das cidades ainda são desconexos e pouco se assemelham com a realidade conectada prevista, possível e desejada. A cidade, a educação e a tecnologia tem de ser para todos. Este é o desafio do futuro!

Segundo a Internet World Stats (cf.: <https://www.internetworldstats.com/stats.htm/>, recuperado em 28 nov. 2018), o Brasil é o quinto maior país do mundo, o sexto país mais populoso e o sétimo país em uso da internet, crescendo sempre desde 2000. No entanto, o acesso à internet, conforme pesquisa da TIC Domicílios realizada anualmente pelo Comitê Gestor da Internet (CGI), compreende cinquenta por cento das residências, onde a qualidade da conexão depende do grau de renda e região. "Enquanto $96 \%$ das famílias brasileiras de alta renda têm internet de alta velocidade, $2 \%$ da população com menor poder de compra ainda usa internet discada",como informa a Agência Brasil (cf.: <https://jconline.ne10.uol.com.br/canal/economia/nacional/noticia/ 2016/01/17/acesso-a-internet-e-desigual-no-brasil-217308.php/>, recuperado em 28 nov. 2018). Em corroboração com esta reflexão, a UNICEF apresenta dados importantes para serem analisados:

$O$ acesso à web é considerado pela Unicef um indicador de desigualdade. O relatório Situação Mundial da Infância 2017: as crianças em um mundo digital mostrou que, no mundo, 29\% dos jovens entre 15 e 24 anos não têm acesso à internet. São 346 milhões de pessoas. Na África, esse índice é de 60\%, enquanto na Europa não passa de 4\%. No Brasil, o estudo TIC Domicílios 2017, divulgado no fim de julho pelo Comitê Gestor da Internet (CGI.br), apontou que mais de um terço das residências (27 milhões) não têm acesso à internet. Se consideradas apenas as classes $D$ e E, o índice de desconectados chega a 70\%. O principal motivo é o custo do serviço, seguido da falta de habilidade para navegar na web (UNICEF).

É preciso ter enorme cautela antes de deixar-se seduzir por IOT e cidades smarts como um caminho suave, certo e romântico para a cidade saudável. A seguir uma lista de perspectivas para 
o futuro nos próximos anos, a partir de 2015, segundo um estudo empresarial sobre Tendências e Visões +15 (cf.: <https://gife.org.br/estudo-aponta-tendencias-para-a-sociedade-nos-proximos-15anos/>, <http://fundacaotelefonica.org.br/tendencias15/>, <https://www.youtube.com/watch?

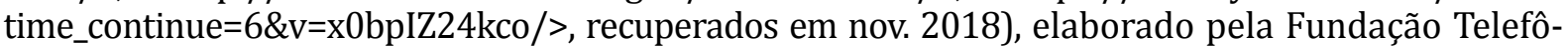
nica Vivo que parece interessante, especialmente por partir da percepção dos colaboradores:

Em 2015, foram identificados 15 temas/tendências: Autoformação e novas formas de aprendizagem; Ativismo e representação social; Novas fronteiras legais; Life Tracking; Pluralidade e Diversidade; Novas formas de trabalho e carreira; Consciência e bem-estar; Hiperconexão; Reconfiguração das cidades; Inteligência Artificial; Convergência Tecnológica; Produção descentralizada; Economia de recursos; Consumo compartilhado; e Novos Modelos de Investimento Social.

O estudo contempla ainda 60 subtemas, assim como seis cenários possíveis de investimento, com 290 iniciativas inovadoras mapeadas, além das controvérsias das tendências, ou seja, questões que podem ser riscos, mas também apontam caminhos para oportunidades de atuação. Em todas as etapas e iniciativas é necessário fomentar e instrumentalizar o indivíduo e sua comunidade para o exercício de sua cidadania buscando a construção coletiva e participativa nas soluções por cidades inclusivas, saudáveis e educadoras (Fundação Telefônica, <http://fundacaotelefonica.org.br/tendencias15/>).

Outro nome a se destacar para pensar o futuro é Peter Diamandes (cf.: <https://www.diamandis.com/ $>$, recuperado em 28 nov. 2018) que respondeu a seguinte proposta: O Mundo em 2015: 8 Mudanças para os próximos primeiros anos em que são listados oito tópicos que causarão uma transformação extraordinária na maneira como as pessoas se relacionam e nas cidades nas próximas décadas.

1. Um cérebro humano por US $\$ 1.000$.

2. A economia de um trilhão de sensores.

3. Conhecimento perfeito (ser capaz de saber qualquer).

4. Oito bilhões de pessoas hiperconectadas.

5. Grandes mudanças nos atuais sistemas de saúde.

6. Realidade Aumentada.

7. Inteligência Artificial.

8. Blockchain.

Fontes: <https://www.diamandis.com>.

Mesmo em face das iniciativas mundiais para resolver estas questões e dos desafios globais feitos por "pensadores e solucionadores" desta geração por meio de competições lançadas, pelo próprio empresário e multibilionário, Peter Diamandis, sabe-se que os problemas são planetários. Diamandis sugere que para ser um bilionário é preciso ser capaz de impactar a vida de bilhões de pessoas, fomentando a ideia de que a vida de um empreendedor pode salvar muitos.

Ideia esta que não corrobora com o conceito de que a autonomia parte da comunidade para a comunidade e pela comunidade, já que esta segue na direção de um para um bilhão. Na visão de Peter Diamandis, as soluções são consumidas pela maioria e não desenvolvidas pela maioria. Esta mentalidade pode ser perigosa, pois tende a deixar a maioria das pessoas à margem do processo de solução criando uma massa de consumidores ignorantes acerca do problema e da solução.

\section{0 papel dos humanos}

Compreender o papel dos humanos neste processo cada vez mais automatizado, hiper-rápido e conectado da internet das coisas, de máquinas que aprendem (machine learning), inteligência artificial, neural etc., ganha espaço e relevância crescente, sobre tudo porque a solução tecnológica é desconhecida pela maioria, é cada vez mais específica, é boa e funciona por um custo cada vez menor com pouca força de trabalho, ou seja, com o envolvimento de poucas pessoas, mas é feita para produzir destituída do aspecto emocional. 
Portanto, a solução tecnológica em grande escala é uma combinação, simultaneamente, ótima e complexa, embrutecedora e refinada. Embora possa envolver muitos ou poucos usuários, ainda está nas mãos de poucos criadores ou desenvolvedores que, por sua vez, são humanos, mas, cada vez mais, serão humano-máquinas, já que o hibridismo humano-tecnológico constitui uma realidade. Para a maioria das pessoas a solução parece pronta, espontânea, automática ou mágica, entretanto, a realidade é que a maioria das pessoas que consome soluções não tem ideia de como muitos problemas são resolvidos e, cada vez mais, "problema e solução" se tornam distantes do ser humano-consumidor.

Este indivíduo tem perdido a capacidade de envolver-se com a solução do problema, em parte por ter delegado às máquinas e às tecnologias estas tarefas desconhecendo como funcionam e em parte por se tornar progressivamente refém da ignorância cognitiva digital, pois não são educados a pensarem a realidade e muitos nem a percebem. A noção, a sensação de que as barreiras diminuíram, os acessos aumentaram, as conexões são mais abundantes e rápidas em que os apps e a tecnologia resolvem tudo, inquieta-nos, pois nesta realidade somos engolidos pela máquina ou a engolimos na forma de nano equipamentos que monitoram a saúde e aumentam as capacidades e habilidades humanas, sejam motoras ou cognitivas, estendem nossos corpos e controlam as cidades.

Entretanto, a percepção do que acontece e de nossa hibridização, ou de quem faz acontecer e como acontece é cada vez menor ou sutil e embora esta sensação de automatismo e prontidão seja deliciosamente sedutora e propagandeada na forma de sonho, desejo e saúde revela-se perturbadora se compreendermos que a sociedade é composta de pessoas que precisam se engajar, comprometer-se, convencer-se para igualmente melhorarem seus espaços. Viver em uma sociedade potencialmente tecnológica, que esteja a serviço do ser humano e ao alcance de todos de forma inteligente, coletiva, participativa e conhecida pode ser uma a forma de minimizar o império da ignorância onde a tecnologia "pensa" por nós e nós deixamos de pensar e de fazer para sermos consumidores alienados e fascinados.

Se o cidadão estiver ciente e sensibilizado com as mudanças e seus fins, poderá preparar-se melhor para apropriar-se dos recursos tecnológicos e digitais não sendo, ele mesmo apropriado por estes.

Desse modo, poderá ter capacidade de antever os fatos e desenvolver consciência do mundo e da internet das coisas que se conectam entre si, podendo mobilizar sua própria comunidade em prol de soluções que deem conta das intempéries locais do grupo de forma criativa, colaborativa e autônoma.

\section{Referências}

Glenn, J. C. (2009). State of the Future 2009. Disponível em: <http://107.22.164.43/millennium/challeng.html>. Recuperado em 28 nov. 2018.

Harari, Y. N. (2015). Sapiens. Uma breve História da Humanidade (464p.). São Paulo: L\&PM Editores.

Pew Research Center. (s./d.). The Changing Global Religious Landscape. Disponível em: <http:// www.pewforum.org/2017/04/05/the-changing-global-religious-landscape/>. Recuperado em 28 nov. 2018.

OPAS (1996). El Movimiento de MunicipiosSaludables: una Estrategia para laPromoción de la Salud en América Latina, 96, 14, abril.

ONU. (s./d.). Conheça os novos 17 Objetivos de Desenvolvimento Sustentável da ONU. Disponível em: <https://nacoesunidas.org/conheca-os-novos-17-objetivos-de-desenvolvimento-sustentavel-da-onu/>. Recuperado em 28 nov. 2018.

Rodrigues, M. M. (2008). Educação ao longo da vida: a eterna obsolescência humana em Santa Catarina. (Tese de doutorado). Universidade Federal da Fronteira Sul, UFFS/SC, Brasil. 
Skimlinks (s./d.). Singularity University: meet the people who are building our future. Disponível em: <https://www.theguardian.com/technology/2012/apr/29/singularity-university-technology-futurethinkers>. Recuperado em 28 nov. 2018.

Urzelia, I. (1998). Manual de Logística Integral. Madrid: Diaz de Santos.

Waze Co. (s./d.). Disponível em: <https://www.waze.com/pt-BR>. Recuperado em 28 nov. 2018. 